\title{
Short-time weight-bearing capacity assessment for non-ambulatory patients with subacute stroke: reliability and discriminative power
}

Oliver Stoller ${ }^{1,2^{*}}$, Heike Rosemeyer ${ }^{3}$, Heiner Baur ${ }^{4}$, Matthias Schindelholz ${ }^{1,2}$, Kenneth J. Hunt ${ }^{1,2}$, Lorenz Radlinger ${ }^{4}$ and Corina Schuster-Amft ${ }^{1,2}$

\begin{abstract}
Background: Weight-bearing capacity (WBC) on the hemiparetic leg is crucial for independent walking, and is thus an important outcome to monitor after a stroke. A specific and practical assessment in non-ambulatory patients is not available. This is of importance considering the increasing administration of high intensive gait training for the severely impaired stroke population. The aim was to develop a fast and easy-to-perform assessment for WBC on a foot pressure plate to be used in clinical routine.
\end{abstract}

Methods: WBC was assessed in the frontal plane in 30 non-ambulatory patients with subacute stroke and 10 healthy controls under 3 conditions: static, dynamic, and rhythmic. Force-time curves for the hemiparetic leg (patients with stroke) and the non-dominant leg (healthy controls) were normalised as a percentage of body weight (\%BW), and the means analysed over 60, 30, and $15 \mathrm{~s}$ (static) and the mean of the peak values for 15, 10, 5, 4, and 3 repetition trials (dynamic, rhythmic). The data were tested for discriminative power and reliability. Dynamic and rhythmic tests could discriminate between patients with stroke and healthy controls over all periods (15, 10, 5, 4, and 3 repetitions) $(p<0.001)$, but not the static test ( $60 \mathrm{~s}, p=0.639 ; 30 \mathrm{~s}, \mathrm{p}=0.708 ; 15 \mathrm{~s}, \mathrm{p}=0.685)$. Excellent relative intra-session [intra-class correlation (ICC) $>0.829$ ] and inter-session reliability (ICC $=0.740$ ) were found for 3 repetitions in the dynamic test with acceptable absolute reliability [standard error of measurement (SEM) $<5 \%$ BW, minimal detectable difference $(\mathrm{MDD})<12.4 \% \mathrm{BW}$ ] and no within- or between-test differences (trial 1, $p=0.792$; trial 2, $p=0.067$; between trials, $\mathrm{p}=0.102$ ).

Conclusions: Three dynamic repetitions of loading the hemiparetic leg are sufficient to assess WBC in non-ambulatory patients with subacute stroke. This is an important finding regarding the implementation of a fast and easy-toperform assessment for routine clinical usage in patients with limited standing ability.

Keywords: Cerebrovascular accident, Subacute, Rehabilitation, Motor recovery, Clinical routine

\section{Background}

Loading the hemiparetic leg is an important factor in gait retraining and is essential for independent walking after

\footnotetext{
*Correspondence: stolleroliver@gmail.com

${ }^{1}$ Division of Mechanical Engineering, Department of Engineering and Information Technology, Institute for Rehabilitation and Performance Technology, Bern University of Applied Sciences, Pestalozzistrasse 20, 3400 Burgdorf, Switzerland

Full list of author information is available at the end of the article
}

stroke [1]. Weight-bearing capacity (WBC) is therefore an important outcome to monitor and particularly relevant in patients with severe motor impairments who cannot walk independently, thus, are unable to perform established gait assessments.

Considering today's capabilities in technical-assisted rehabilitation after severe stroke, i.e., the administration of high intensive gait training for the severely impaired stroke population, there is a need to assess WBC for 
clinical decision-making and efficacy analyses. Although previous research revealed several modalities to evaluate WBC after stroke [2-8], no rapid assessment exists to evaluate the ability to transfer load to the hemiparetic leg.

The aim was to develop and evaluate a fast and easyto-perform assessment on a foot pressure plate to be used for clinical routine, which is of importance regarding recent advancement in gait rehabilitation of patients with severe motor impairments. This study tested static, dynamic and rhythmic single leg loading in the frontal plane for discriminative power and reliability in order to move the assessment towards practicability.

\section{Methods}

\section{Participants}

Thirty non-ambulatory patients with subacute stroke and 10 healthy controls participated in this study. Participants' characteristics are shown in Table 1. Eligibility criteria for patients with stroke were: age $>18$ years, first-ever stroke within the last 20 weeks, able to stand without support for $60 \mathrm{~s}$, no orthopaedic pathologies, functional ambulation classification $<3$ [9], and ability to understand the procedure. Eligibility criteria for the healthy controls were: age $>18$ years, able to walk without aids, no neurological or orthopaedic pathologies, and no surgery in general within the last 2 years. All participants gave signed informed consent. The ethics committee of the Swiss Canton of Aargau reviewed and approved the study (Ref. 2012/051).

\section{Data collection}

Participants performed two trials on separate days. A foot pressure plate (FDM-S, zebris Medical GmbH, Isny i.A., Germany; width $540 \mathrm{~mm}$, length $340 \mathrm{~mm}$, sampling rate $50 \mathrm{~Hz}$ ), based on calibrated capacitive force sensors was used to measure the static and dynamic forces under each foot. Participants were placed in a standard standing position (both legs on the foot pressure plate, heels $100 \mathrm{~mm}$ apart, leg rotation chosen freely) within parallel bars, wearing flat closed shoes, with arms hung aside the body and eyes open. Two trained physical therapists helped the patients with stroke to get up from the wheelchair to stand directly on the foot pressure plate. All participants were allowed to hold the parallel bars during positioning of the feet, which was done by the physical therapists. The standardised parallel bars (height $100 \mathrm{~cm}$ ) were positioned outside of the participant's range of motion for psychological comfort and safety reasons. At any time, a trained physical therapist stood in the range for supervision or physical assistance if needed.

All participants were instructed to: (1) stand as still and balanced as possible for $60 \mathrm{~s}$ (static); (2) alternately shift the body weight in the frontal plane as far as possible sideways at a self-selected frequency for $60 \mathrm{~s}$ (dynamic), and (3) alternately shift the body weight in the frontal plane as far as possible sideways at a given pace ( 45 beats/min controlled by a digital metronome) for $60 \mathrm{~s}$ (rhythmic) without holding the parallel bars (for a typical sequence please see Fig. 1). Complete foot contact to the foot pressure plate, no knee hyperextension, knee flexion $<20^{\circ}$, and no forced hip abduction/adduction during all the tests were essential to successfully accomplish the test protocol (supervised by a trained physical therapist). There was $60 \mathrm{~s}$ rest in a sitting position between the 3 test modalities and exactly $48 \mathrm{~h}$ between the two sessions. All participants performed 1 trial in static, dynamic, and rhythmic condition per session.

\section{Data processing}

Force-time curves for the hemiparetic leg (patients with stroke) and the non-dominant leg (healthy controls) were calculated and normalised as a \%BW (non-dominant

Table 1 Participants' characteristics

\begin{tabular}{llll}
\hline & Patients with stroke $(\mathbf{n}=\mathbf{3 0})$ & Healthy controls $(\mathbf{n}=\mathbf{1 0})$ & $\boldsymbol{p}$ value* \\
\hline Men/women & $19 / 11$ & $4 / 6$ & \\
Age (years) & $63.6 \pm 11.6(41-82)$ & $79.0 \pm 12.7(32-77)$ & 0.379 \\
Body mass (kg) & $77.0 \pm 17.9(51-123)$ & $1.7 \pm 0.1(1.6-1.9)$ & 0.396 \\
Height $(\mathrm{m})$ & $1.7 \pm 0.1(1.6-1.9)$ & $24.7 \pm 2.4(19.7-27.5)$ & 0.818 \\
Body mass index $\left(\mathrm{kg} / \mathrm{m}^{2}\right)$ & $26.6 \pm 5.7(18.5-40.2)$ & & \\
Type of stroke: ischemic/haemorrhagic & $21 / 9$ & & \\
Hemiparetic side: right/left & $18 / 12$ & & \\
Ankle splint: yes/no & $4 / 26$ & & \\
Time post-stroke (weeks) & $7.4 \pm 4.2(2.1-17.7)$ & & \\
Functional ambulation classification: $0-5$ & $1.4 \pm 0.7(0-2)$ & &
\end{tabular}

Values are given in absolute numbers ( $\mathrm{n}$ ) or mean \pm standard deviation (range)

* Mann-Whitney U test 


\section{Patient with stroke}

\section{Static}

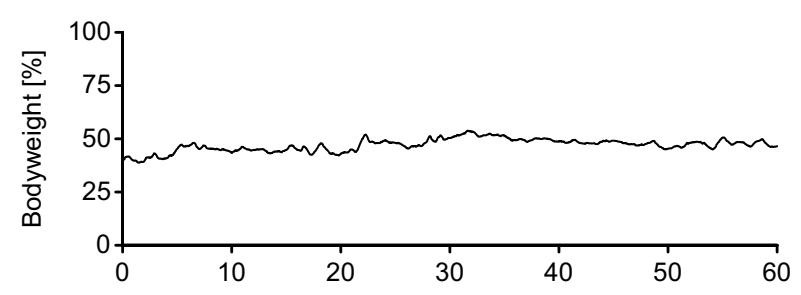

\section{Dynamic}

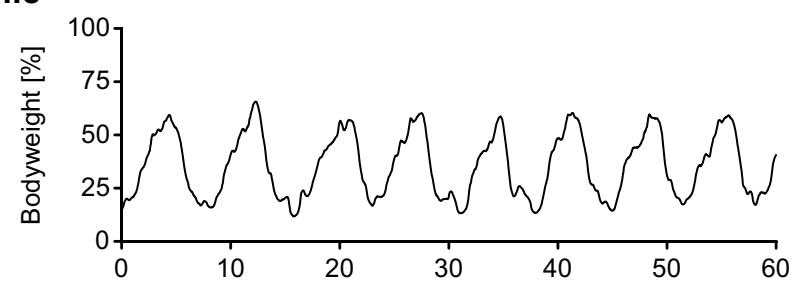

Healthy control

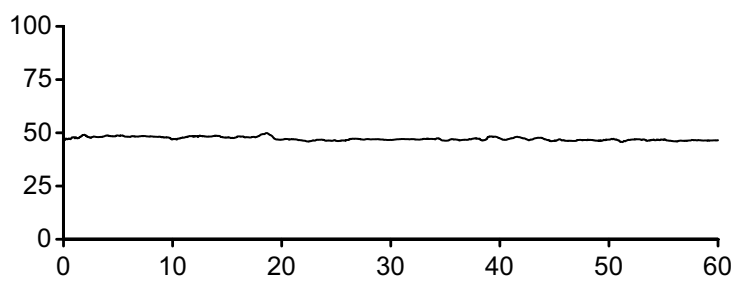

Rhythmic
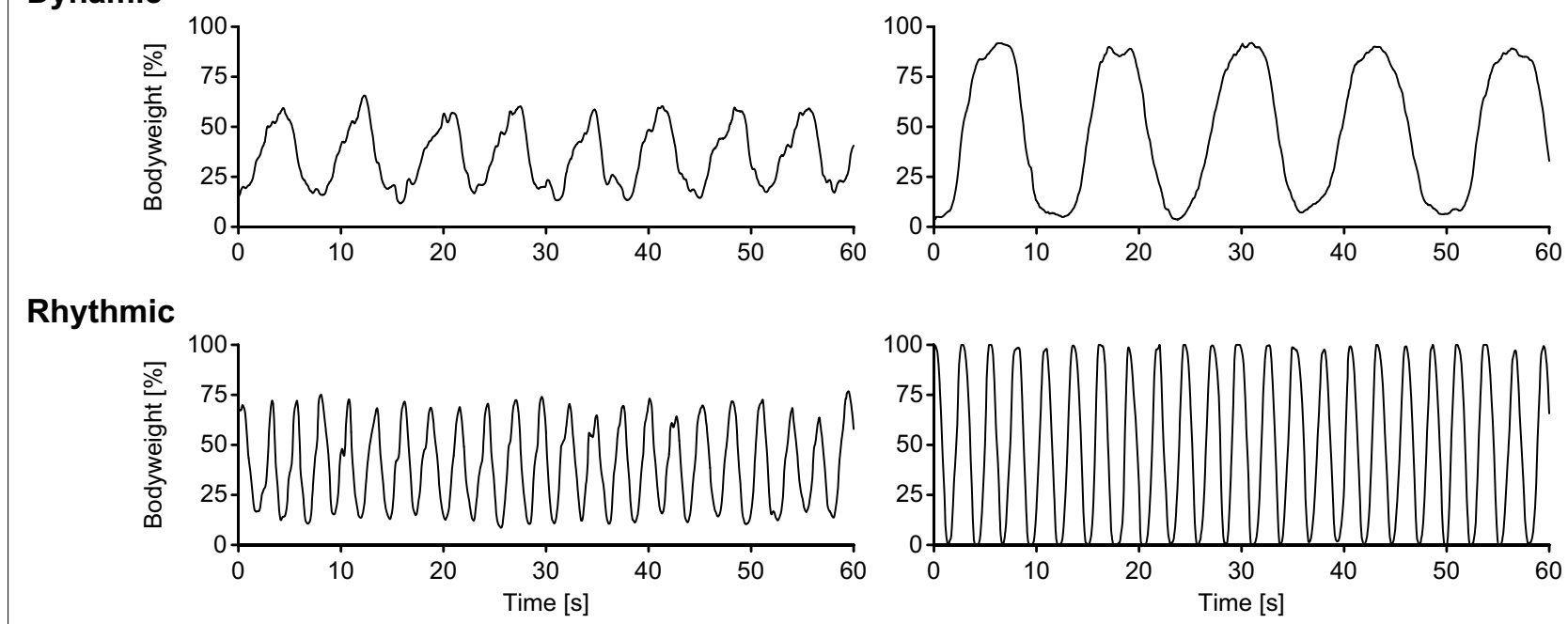

Fig. 1 Typical test sequence. Force-time curves of a patient with subacute stroke (left) and a healthy control (right) during the test battery (static, dynamic, rhythmic)

led $=$ leg with lower $\% \mathrm{BW}$ in the static condition). For the static measurement, WBC was defined as the mean value of total \%BW and was calculated for 60,30 , and $15 \mathrm{~s}$. WBC for the dynamic and the rhythmic modality measures was defined as the mean of the peak \%BW values (Fmax), representing the amount of single leg loading capacity. It was estimated for $15,10,5,4$, and 3 repetitions. Data processing was performed using customised software (ads, Version 4.01, UK Labs, Kempten, Germany).

\section{Statistical analysis}

Differences between groups (patients with stroke vs. healthy controls) were evaluated with the Mann-Whitney $U$ test. Intra-session and inter-session reliability were quantified using intra-class correlation coefficients $\left(\mathrm{ICC}_{2,1}\right)$. Absolute reliability was determined by estimating the standard error of the measurement [SEM $=$ standard deviation of the difference (SDdiff) $\sqrt{1-\mathrm{ICC}}]$ and the minimal detectable difference (MDD $=1.96$ $\times \sqrt{ } 2 \times \mathrm{SEM})$ [10]. The Friedman test was used for intra-session comparisons of Fmax values, and the
Wilcoxon test was applied for between-session comparisons of Fmax values. Two-sided $\mathrm{p}$ values $\mathrm{p} \leq 0.05$ were considered significant. Statistical analyses were performed using SPSS (version 20.0, IBM, Armonk NY, USA).

\section{Findings}

WBC was significantly different between patients with stroke and healthy controls over all periods $(15,10,5$, 4 , and 3 repetitions) in the dynamic test $(\mathrm{p}<0.001)$ and the rhythmic test $(\mathrm{p}<0.001)$, but not in the static test $(60 \mathrm{~s}, \mathrm{p}=0.639 ; 30 \mathrm{~s}, \mathrm{p}=0.708 ; 15 \mathrm{~s}, \mathrm{p}=0.685)$. Further analyses in patients with stroke showed that 3 repetitions in the dynamic test (dynamic Fmax3), the fastest and easiest setup, had excellent relative intra-session $[\mathrm{T} 1, \mathrm{ICC}=0.843$ (confidence interval (CI) $95 \% 0.735-$ 0.915); T2, ICC $=0.829$ (CI $95 \% 0.715-0.908)$ ] and intersession reliability $(\mathrm{ICC}=0.740$ (CI $95 \% 0.517-0.868)$ ) with acceptable absolute reliability (SEM $<5 \% \mathrm{BW}$, $\mathrm{MDD}<12.4 \% \mathrm{BW})$. No intra- and inter-session differences ( $\mathrm{T} 1, \mathrm{p}=0.792 ; \mathrm{T} 2, \mathrm{p}=0.067$; $\mathrm{T} 1 / \mathrm{T} 2, \mathrm{p}=0.102$ ) were detected (Table 2). Although the shortest setup 


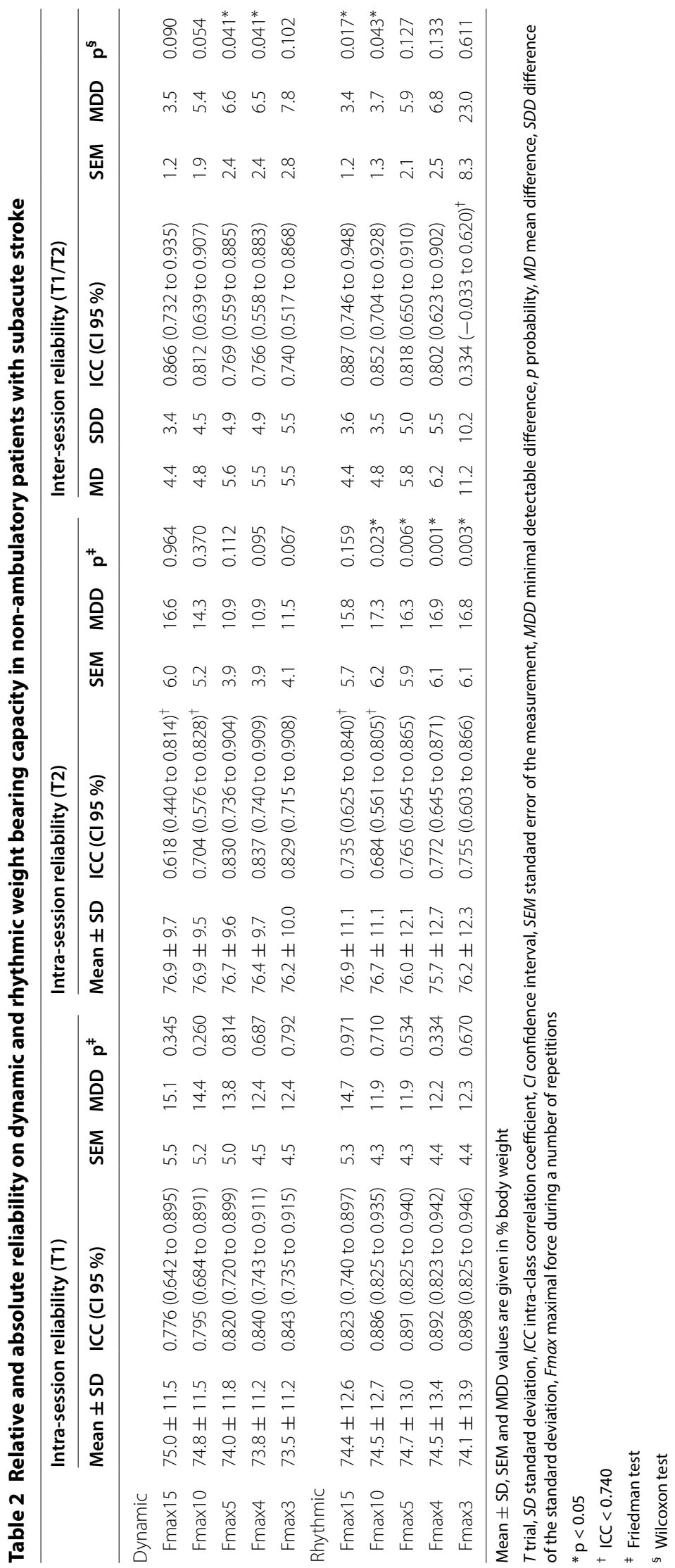


in the rhythmic test (rhythmic Fmax3) showed similar relative intra-session reliability $(\mathrm{T} 1, \mathrm{ICC}=0.898$; $\mathrm{T} 2$, ICC > 0.755) compared to the dynamic test (dynamic Fmax3), intra-session differences during T2 were significant $(\mathrm{p}=0.003)$ with low relative inter-session reliability $[\mathrm{ICC}=0.334(\mathrm{CI} 95 \%-0.033$ to 0.620$)]$.

\section{Discussion}

A fast and easy-to-perform assessment to evaluate WBC in non-ambulatory patients with subacute stroke was developed and evaluated in order to provide a practical tool for clinical decision-making and efficacy analyses. The assessment can discriminate between patients with stroke and healthy controls and was shown to be highly reliable. It can be applied in a variety of clinical settings, and could be used to evaluate WBC in severely impaired patients with limited standing ability within the rehabilitation routine. In particular, patients early after stroke with severe hemiparesis suffer from de-conditioning and limited motor control, which restricts extended assessment of physical function. The introduction of dynamic repetitions within a short period of time to evaluate WBC is therefore of high importance for this population.

Previous studies have reported high intra-session reliability for forward and lateral weight shifting [2], good intra-session reliability for the body centre of mass displacement when transferring weight laterally into a single-leg posture [6], and high inter-session reliability over 2 separate days for WBC during different standing tasks [3]. In addition to the similar relative and absolute reliability results compared to previous research, this is the first study that condenses the assessment protocol into a single evaluation making it applicable for clinical routine. Although rhythmic facilitation during WBC was less reliable in this study, it presents an option to control execution speed during weight shifting/walking tasks, as a previous study has shown to increase effort in gait rehabilitation with acute stroke patients [11].

In contrast to previous research on weight distribution among patients with stroke $[12,13]$, this study found no significant between-group differences in weight bearing capacity in the static condition (also described as preferred weight distribution). This might be due to the instruction during the trials, which was: "to stand as still and balanced as possible" for $60 \mathrm{~s}$. It must be hypothesised that avoidance of this instruction might have led to significant differences in weight distribution between patients with subacute stroke and healthy controls.

The present study has some limitations. A foot pressure plate has been used to evaluate force-time curves rather than a force plate, considered as the gold standard for weight distribution analyses. However, this study aimed to develop an assessment for routine clinical usage, which justifies the usage of a low-cost measurement device. The eligibility criteria on standing function limit the external validity of the proposed assessment. The instructions permitted participants to perform the movement in a comfortable way, rather than constraining the task with more specific instructions (e.g., standardise lateral hip and trunk displacement). The sample size was rather small to generalise the findings and propose recommendations for clinical practice. Future investigations will obtain longitudinal data with a larger sample to establish the usability and the predictability of the measurement. Furthermore, data on concurrent validity are of high importance, and the gold standard to rapidly assess WBC in a clinical environment needs to be determined. Other variables such as awareness, attention, and coordination that influence WBC might also be taken into account $[14,15]$.

In conclusion, 3 dynamic repetitions of loading the hemiparetic leg on a foot pressure plate are sufficient to assess WBC in non-ambulatory patients with subacute stroke. This is an important finding regarding the development and implementation of a fast and easy-toperform assessment for routine clinical usage in patients with limited standing ability.

\section{Abbreviations}

WBC: Weight-bearing capacity; BW: Body weight; ICC: Intra-class correlation; SEM: Standard error of measurement; MDD: Minimal detectable difference; $\mathrm{Cl}$ : Confidence interval.

\section{Authors' contributions}

$\mathrm{OS}, \mathrm{HR}, \mathrm{HB}$, and $L R$ were responsible for the design and the methodology of the study. OS and CSA accomplished the ethical approval. OS and HR carried out the experiments. MS was responsible for the technical development and maintenance. OS, HR, HB, and LR performed the statistical analysis. OS and $H R$ drafted the manuscript. $H B$, $L R$, and $K J H$ supervised the process and provided expertise. All authors read and approved the final manuscript.

\section{Author details}

${ }^{1}$ Division of Mechanical Engineering, Department of Engineering and Information Technology, Institute for Rehabilitation and Performance Technology, Bern University of Applied Sciences, Pestalozzistrasse 20, 3400 Burgdorf, Switzerland. ${ }^{2}$ Research Department, Reha Rheinfelden, Salinenstrasse 98, 4310 Rheinfelden, Switzerland. ${ }^{3}$ Physiotherapy Department, Reha Rheinfelden, Salinenstrasse 98, 4310 Rheinfelden, Switzerland. ${ }^{4}$ Division of Health, Applied Research and Development Physiotherapy, Bern University of Applied Sciences, Murtenstrasse 10, 3008 Bern, Switzerland.

\section{Acknowledgements}

The authors thank Prof. Dr. Thierry Ettlin, Prof. Dr. Stefan Nehrer, Dr. Gisela Büchele and Benjamin Stiehl for their support and advice.

\section{Competing interests}

The authors declare that they have no competing interests.

Received: 25 May 2015 Accepted: 19 November 2015

Published online: 26 November 2015 


\section{References}

1. Brunnstrom $S$. Walking preparation for adult patients with hemiplegia. Phys Ther. 1965;45:17-29.

2. Goldie PA, Matyas TA, Evans OM, Galea M, Bach TM. Maximum voluntary weight-bearing by the affected and unaffected legs in standing following stroke. Clin Biomech. 1996;11(6):333-42.

3. Eng JJ, Chu KS. Reliability and comparison of weight-bearing ability during standing tasks for individuals with chronic stroke. Arch Phys Med Rehabil. 2002;83(8):1138-44.

4. Mercer VS, Freburger JK, Chang SH, Purser JL. Measurement of pareticlower-extremity loading and weight transfer after stroke. Phys Ther. 2009;89(7):653-64. doi:10.2522/ptj.20080230.

5. Geurts AC, de Haart M, van Nes IJ, Duysens J. A review of standing balance recovery from stroke. Gait Posture. 2005;22(3):267-81. doi:10.1016/j. gaitpost.2004.10.002.

6. Pai YC, Rogers MW, Hedman LD, Hanke TA. Alterations in weight-transfer capabilities in adults with hemiparesis. Phys Ther. 1994;74(7):647-57

\section{(discussion 657-659).}

7. de Haart M, Geurts AC, Dault MC, Nienhuis B, Duysens J. Restoration of weight-shifting capacity in patients with postacute stroke: a rehabilitation cohort study. Arch Phys Med Rehabil. 2005;86(4):755-62. doi:10.1016/j. apmr.2004.10.010.

8. Hurkmans HL, Bussmann JB, Benda E, Verhaar JA, Stam HJ. Techniques for measuring weight bearing during standing and walking. Clin Biomech. 2003;18(7):576-89.
9. Holden MK, Gill KM, Magliozzi MR, Nathan J, Piehl-Baker L. Clinical gait assessment in the neurologically impaired. Reliability and meaningfulness. Phys Ther. 1984;64(1):35-40.

10. Weir JP. Quantifying test-retest reliability using the intraclass correlation coefficient and the SEM. J Strength Cond Res. 2005;19(1):231-40. doi:10.1519/15184.1.

11. Thaut MH, McIntosh GC, Rice RR. Rhythmic facilitation of gait training in hemiparetic stroke rehabilitation. J Neurol Sci. 1997;151(2):207-12.

12. Tessem S, Hagstrom N, Fallang B. Weight distribution in standing and sitting positions, and weight transfer during reaching tasks, in seated stroke subjects and healthy subjects. Physiother Res Int. 2007;12(2):82-94.

13. Caldwell C, Macdonald D, Macneil K, McFarland K, Turnbull GI, Wall JC. Symmetry of weight distribution in normals and stroke patients using digital weigh scales. Physiother Theory Pract. 1986;2(3):109-16.

14. Genthon N, Rougier P, Gissot AS, Froger J, Pelissier J, Perennou D. Contribution of each lower limb to upright standing in stroke patients. Stroke. 2008;39(6):1793-9. doi:10.1161/STROKEAHA.107.497701.

15. Brown LA, Sleik RJ, Winder TR. Attentional demands for static postural control after stroke. Arch Phys Med Rehabil. 2002;83(12):1732-5. doi:10.1053/apmr.2002.36400.

\section{Submit your next manuscript to BioMed Central and we will help you at every step:}

- We accept pre-submission inquiries

- Our selector tool helps you to find the most relevant journal

- We provide round the clock customer support

- Convenient online submission

- Thorough peer review

- Inclusion in PubMed and all major indexing services

- Maximum visibility for your research

Submit your manuscript at www.biomedcentral.com/submit
() Biomed Central 